\title{
Nanomineralogy of the First Solids in the Solar System: Discovering New Minerals and New Materials
}

\author{
Chi $\mathrm{Ma}^{1}$
}

${ }^{1}$ Division of Geological and Planetary Sciences, California Institute of Technology, Pasadena, CA 91125, USA; Email: chi@gps.caltech.edu

Nanomineralogy is the study of Earth and planetary materials at nano-scales, focused on characterizing nanofeatures (like inclusions, exsolution, zonation, coatings, pores) in minerals and revealing nanominerals and nanoparticles [1,2]. With advanced high-resolution analytical scanning electron microscopy, we are now capable to characterize solid materials in situ easier and faster down to nano-scales [3]. During our ongoing nanomineralogy investigation of meteorites since 2007, more than 20 new minerals have been discovered. Each of the new extraterrestrial minerals reveals distinctive forming environments with intensive variables (e.g., composition, temperature, pressure, $\mathrm{fO}_{2}$ ), providing new insights into nebula or parent-body processes. 10 of them are refractory minerals, including allendeite $\left(\mathrm{Sc}_{4} \mathrm{Zr}_{3} \mathrm{O}_{12}\right)$ and hexamolybdenum $(\mathrm{Mo}, \mathrm{Ru}, \mathrm{Fe})$ [4], tistarite $\left(\mathrm{Ti}_{2} \mathrm{O}_{3}\right)$ [5], panguite $\left[\left(\mathrm{Ti}^{4+}, \mathrm{Al}, \mathrm{Sc}, \mathrm{Mg}, \mathrm{Zr}, \mathrm{Ca}, \square\right)_{2} \mathrm{O}_{3}\right][6]$, kangite [( $\left.\left.\mathrm{Sc}, \mathrm{Ti}, \mathrm{Al}, \mathrm{Zr}, \mathrm{Mg}, \mathrm{Ca}, \mathrm{n}\right)_{2} \mathrm{O}_{3}\right]$ [7], davisite $(\mathrm{CaScAlSiO})_{6}$ [8], grossmanite $\left(\mathrm{CaTi}^{3+} \mathrm{AlSiO}_{6}\right)$ [9], paqueite $\left[\mathrm{Ca}_{3} \mathrm{TiSi}_{2}\left(\mathrm{Al}_{2} \mathrm{Ti}\right) \mathrm{O}_{14}\right]$ [10], and krotite $\left(\mathrm{CaAl}_{2} \mathrm{O}_{4}\right)$ [11]. They are among the first solids formed in the solar nebula. To date, $\sim 45$ refractory minerals plus about 15 presolar minerals mark the beginning of the solar mineral evolution. There are now about 4800 mineral species identified on Earth. Minerals in the solar system evolved as a consequence of physical, chemical and biological processes over the past 4.568 billion years [12].

Presented here are a few new refractory minerals (including panguite, kangite, allendeite and tistarite) from the Allende meteorite and demonstrate how nanomineralogy works with an integrated EPMA-SEM-EDS-EBSD approach. EPMA, pioneered by Castaing, is one of the most important research tools in Earth sciences [13], which is responsible for discovery and/or chemical composition determination of new minerals since 1960s. Field emission SEM is widely available nowadays for nanoimaging with EDS for fast elemental analysis and EBSD for crystal structure and orientation studies. EBSD has been used successfully for structure determination of new minerals since 2006 [14].

Panguite (IMA 2010-057) is a high-temperature titania mineral with a cation-deficient Pbca bixbyite-related structure and a formula unit (Ti, $\mathrm{Al}, \mathrm{Sc}, \mathrm{Mg}, \mathrm{Zr}, \mathrm{Ca})_{1.8} \mathrm{O}_{3}$, occurring with davisite (a newly-approved Sc-rich clinopyroxene [8]) in ultra-refractory inclusions from Allende [6] and Murchison, as shown in Fig. 1. The empirical chemical formula of type panguite by EPMA is $\left[\left(\mathrm{Ti}_{0.75} \mathrm{Zr}_{0.15} \mathrm{Si}_{0.07}\right)^{4+}{ }_{\Sigma 0.97}\left(\mathrm{Al}_{0.21} \mathrm{Sc}_{0.20} \mathrm{Y}_{0.06} \mathrm{~V}_{0.02} \mathrm{Cr}_{0.01}\right)^{3+}{ }_{\Sigma 0.5}\left(\mathrm{Mg}_{0.17} \mathrm{Ca}_{0.10} \mathrm{Fe}_{0.04}\right)^{2+}{ }_{\Sigma 0.31}\right]_{\Sigma 1.78} \mathrm{O}_{3}$. EBSD patterns of panguite imply a $\mathrm{CaF}_{2}$-type structure, which assisted in identifying its bixbyite-related structure (a defect form of the $\mathrm{CaF}_{2}$ structure) by synchrotron diffraction [6].

Nature shows many advantages over technology on materials synthesis. The knowledge of minerals can be used for getting inspired on making new materials with useful properties [15]. Panguite and kangite are not only new minerals but also new materials from the solar nebula, which can be exploited for finding engineering materials. 


\section{References}

[1] C. Ma, Eos Trans. $A G U, 89$ (2008), abs MR12A-01.

[2] C. Ma, American Mineralogist, 95 (2010) 188-191.

[3] C. Ma and G.R. Rossman, Microscopy and Microanalysis, 13 (Suppl. 2) (2007) 164-165.

[4] C. Ma et al., American Mineralogist, 99 (2014) in press. DOI: 10.2138/am.2014.4667.

[5] C. Ma and G.R. Rossman, American Mineralogist, 94 (2009) 841-844.

[6] C. Ma et al., American Mineralogist, 97 (2012) 1219-1225.

[7] C. Ma et al., American Mineralogist, 98 (2013) 870-878.

[8] C. Ma and G.R. Rossman, American Mineralogist, 94 (2009) 845-848.

[9] C. Ma and G.R. Rossman, American Mineralogist, 94 (2009) 1491-1494.

[10] C. Ma, Mineralogical Magazine, 77 (2013) 3002.

[11] C. Ma et al., American Mineralogist, 96 (2011) 709-715.

[12] R.M. Hazen et al., American Mineralogist, 93 (2008) 1693-1720. [13] K.

Keil, Microscopy and Microanalysis, 5 (Suppl. 2) (1999) 572-573.

[14] C. Ma and G.R. Rossman, American Mineralogist, 93 (2008) 154-157.

[15] W. Depmeier, Crystal Research and Technology, 44 (2009) 1122-1130.

[16] EPMA, SEM, EDS and EBSD analyses were carried out at the Caltech GPS Division Analytical Facility, which is supported, in part, by NSF grants EAR-0318518 and DMR-0080065. I would like to thank my collaborators G.R. Rossman (Raman), J.R. Beckett (meteorite), O. Tschauner (synchrotron), H.C. Connolly Jr (meteorite), A.N. Krot (meteorite), A.R. Kampf (XRD) and T.J. Zega (TEM), for joining me on this exciting journey of discoveries.

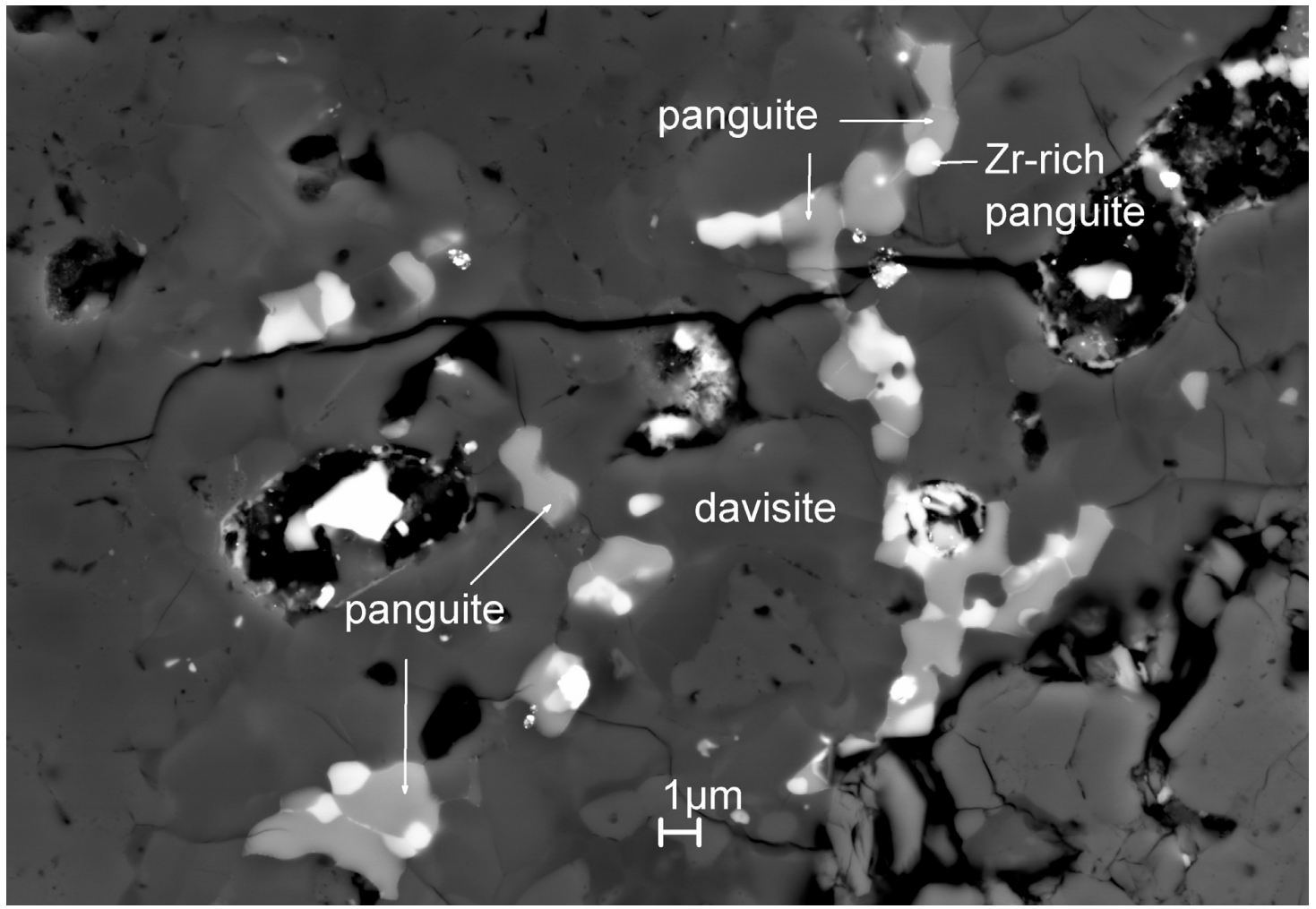

FIG. 1. Back-scatter electron image showing panguite with davisite in an ultra-refractory inclusion within an Allende amoeboid olivine aggregate. 